and carcinoma of the colon, and it may not be too far-fetched to suggest a common cause. Megakaryocytes and platelets have been shown to play an important part in viral multiplication in certain forms of cancer in animals (de Harven and Friend, 1960 ; Gross, 1963), and more recently thrombocytosis has been reported in human cancer (Levin and Conley, 1964). My own observations are in agreement with the views of the latter worker. In these circumstances the immune-suppressant role of these drugs may well be a disadvantage, and perhaps provide an explanation for both the failure of these drugs to cure and the severity of the relapses. The beneficial action of the drugs could then be attributed to an antiviral action.

Further support for this view comes from recent observations on cancer chemotherapy in animals (Groupé and Rauscher, 1965 ) and the therapy of Burkitt's lymphoma in man (Burkitt et al., 1965).

\section{Summary}

Observations on a small group of patients suffering from ulcerative colitis and treated with antimetabolites are reported.
While the effect of chemotherapy is at times dramatic, the successful use of the drugs requires adequate facilities and careful control.

While most patients have shown a steady return to normal in all parameters, the failure to achieve cure has been disappointing.

The role of the platelet is discussed, and it is suggested that these observations support a viral infection rather than an autoimmune basis for the disease.

\section{REFERENCES}

Bean, R. H. D. (1962). Med. F. Aust., 49, 592.

(1966). Proceedings of the Xth International Congress of Haemato$\log y, 1964$. In press.

Burkitt, D., Hutt, M. S. R., and Wright, D. H. (1965). Cancer, 18, 399. de Harven, E., and Friend, C. (1960). Nat. Cancer Inst. Mongr., 4, 291. Gross, (1963). 16th Symposium on Fundamental Cancer Research, Texas, '1962, 403. Harper,'London

Groupé, V., and Rauscher, F. J. (1965). Cancer Chemother. Rep., 44, 1. Kirsner, J. B. (1961). Gastroenterology, 40, 287.

Levin, J., and Conley, C. L. (1964). Arch. intern. Med., 114, 497.

McKay, I. R., and Burnet, F. M. (1963). Auto-immune Diseases. Thomas, Springfield, Illinois.

\title{
Comparison of Three Methods for Treatment of Congenital Clubfoot
}

\author{
N. E. SHAW,* CH.M., F.R.C.S.
}

Brit. med.F., 1966, 1, 1084-1086

It is one of the paradoxes of modern surgery that although therapeutic facilities have never been so plentiful disappointing results still occur. In particular, this is true in the treatment of congenital clubfoot.

Brockman (1930) pointed out that everyone agreed that in the infant the proper treatment is repeated manipulation combined with some form of fixation of the foot. The method by which fixation is carried out varies according to the surgeon, and, as Sir Robert Jones (1894) remarked, different methods can give the same result.

In the past ten years three principal methods of fixation have been used in the treatment of clubfoot at the Hospital for Sick Children. None was entirely satisfactory, but the impression that one method was more successful than the others indicated the need for a detailed analysis. A comparison of three different methods of treatment of clubfoot has not hitherto been published; most reports are concerned with one method in the hands of one surgeon. The results presented here form part of a much larger survey designed to show the causes of failure in each of these methods.

\section{Present Series}

Among the 140 patients reviewed boys (96) were more commonly affected than girls (44). There were 81 bilateral cases ( 59 in boys and 22 in girls) and 59 unilateral cases ( 37 in boys and 22 in girls). An analysis of the patients is shown in Table I.

Criteria for Selection of Patients.-Only patients with idiopathic talipes equinovarus were included in the series (Brockman's (1930) type 1 deformity). Children with overt

* From the Hospital for Sick Children, Great Ormond Street, London. Senior Registrar and Clinical Research Assistant, The Institute of Orthor Registrar, London. Now Consultant Surgeon to the Department of Orthopaedics, the Royal Infirmary, Manchester. neurological abnormalities such as spina bifida or muscular disorders such as arthrogryposis were excluded. All the elements of congenital talipes equinovarus must have been present. In addition, if correction of all the deformities was obtained at the first treatment the child was excluded. In all children in the series initial treatment started within one month of birth, in our clinics, and the method must have remained unchanged. Children qualified for assessment only when they were walking, which is better than taking a certain age as the criterion. In fact the youngest children in the series were over two years of age; the eldest was 10.

Criteria of Correction.-The aim of treatment is to obtain a foot with active eversion and active dorsiflexion at the ankle above the right angle. The term "overcorrection" was not used ; what is called "overcorrection" is no more than the valgus and calcaneus position that the normal foot can be made to assume. Likewise, the term "relapse" was considered to indicate a foot that had never been fully corrected by primary treatment. The hallmark of success is a child walking on a mobile plantigrade foot with the heel down and in neutral or slight valgus position and a satisfactory longitudinal arch.

TABLE I

\begin{tabular}{|c|c|c|c|c|c|c|c|}
\hline & \multirow{3}{*}{. } & \multicolumn{2}{|c|}{$\begin{array}{c}\text { Denis Browne } \\
\text { Splint }\end{array}$} & \multicolumn{2}{|c|}{$\begin{array}{c}\text { Robert Jones's } \\
\text { Strapping }\end{array}$} & \multicolumn{2}{|c|}{$\begin{array}{c}\text { Serial } \\
\text { Plasters }\end{array}$} \\
\hline & & Cases & Feet & Cases & Feet & Ca ses & Feet \\
\hline & & 63 & 105 & 62 & 96 & 15 & 20 \\
\hline $\begin{array}{l}\text { Age at } \\
\text { follow-up }\end{array}$ & $\begin{array}{l}\text { Average age-years } \\
\text { Minimum age } \quad . \\
\text { Maximum }, \quad \ldots\end{array}$ & $\begin{array}{r}7 \\
2 \\
10 \\
\end{array}$ & & $\begin{array}{l}5 \\
2 \\
6 \\
\end{array}$ & & $\begin{array}{l}6 \\
2 \\
8 \\
\end{array}$ & \\
\hline $\begin{array}{c}\text { Male } \\
(96)\end{array}$ & $\begin{array}{l}\text { Unilateral } \\
\text { Bilateral }\end{array}\left\{\begin{array}{l}\text { Right } \\
\text { Left }\end{array}\right.$ & $\begin{array}{r}6 \\
5 \\
31\end{array}$ & \} $\begin{array}{l}11 \\
62\end{array}$ & $\begin{array}{r}11 \\
8 \\
26\end{array}$ & \} $\begin{array}{l}19 \\
52\end{array}$ & $\begin{array}{l}3 \\
4 \\
2\end{array}$ & \} $\begin{array}{l}7 \\
4\end{array}$ \\
\hline$\underset{(44)}{\text { Female }}$ & $\begin{array}{l}\text { Unilateral } \\
\text { Bilateral }\end{array}\left\{\begin{array}{l}\text { Right } \\
\text { Left }\end{array}\right.$ & $\begin{array}{r}3 \\
7 \\
11\end{array}$ & $\left\{\begin{array}{l}10 \\
22\end{array}\right.$ & $\begin{array}{l}5 \\
4 \\
8\end{array}$ & $\begin{array}{r}9 \\
16\end{array}$ & $\begin{array}{l}3 \\
0 \\
3\end{array}$ & \} $\begin{array}{l}3 \\
6\end{array}$ \\
\hline
\end{tabular}


Both the forefoot and the hind-foot must be corrected clinically and radiographically. Lateral and dorsal radiographs of the feet with the patient standing were taken in clinically doubtful cases. A persistent equinus deformity of the calcaneum ("rocker-bottom" or "boat-shaped" foot or " mid-tarsal breach") was considered to indicate lack of correction and predisposing to so-called relapse. Though a foot might be good functionally in spite of imperfect correction, this was not accepted as success. Any form of surgical intervention was regarded as an admission of failure of conservative care. Therefore, from the point of view of the usefulness of primary management, the patients were divided into only two groups: successful and unsuccessful.

\section{Methods Used in the Primary Treatment}

Three techniques were used in the primary correction.

1. The Denis Browne splint (Denis Browne, 1937, 1956). A thick pad of several layers of adhesive felt is attached to the foot under the cuboid bone. The horizontal foot-piece is then applied to bring the foot into valgus when the vertical legpiece is strapped to the leg. The two foot-pieces of the splints are connected by the horizontal bar. The splint is changed weekly for the first three to four weeks and fortnightly thereafter.

2. Gentle manipulation or stretching is carried out to correct the deformity, and correction is maintained by adhesive strapping; a method used by Robert Jones (Jones and Lovett, 1929). Stretching is carried out at least three times weekly by the surgeon or physiotherapist, and the mother is instructed to stretch the foot at each feed or each time the diaper is changed. More strapping is applied over the original strapping once or twice each week, as more correction is obtained by repeated stretching. Strapping is changed weekly to maintain the correction.

3. Manipulation and serial plaster-of-Paris casts.

When primary correction had been obtained by each of these methods of treatment fixation was changed to the Denis Browne bootee or the equinus splint.

\section{Results}

The results of treatment of 221 feet were reviewed. Of 105 feet treated by Denis Browne splints only 20 (19\%) were corrected by conservative treatment alone, contrasting with 68 feet out of $96(71 \%)$ corrected by Robert Jones's stretching and strapping. Only 20 feet were treated by manipulation and serial plasters, but all of these required operation. In the series treated by Denis Browne splints 73 feet $(70 \%)$ had been treated subsequently by either soft-tissue or bony operations. Fifteen $(14 \%)$ of these feet had been treated by bony operations such as wedge resection of the tarsus, often at the early age of 4 years. In 46 feet $(43 \%)$ correction of the calcaneal equinus by elongation of the tendo calcaneus had been attempted, but in 12 patients this was carried out over the age of 9 years and in four patients after bony operations to the mid-tarsal region.

Only 14 feet (14\%) treated by Robert Jones's stretching and strapping had been operated on ; in all these cases early elongation of the tendo calcaneus had been performed, in some instances with posterior capsular release. The average age at operation was 18 months. Several of these operations were carried out at 3 months with complete correction of the rockerbottom deformity for which they were performed. Only five $(5 \%)$ of these feet required further operation, and this involved a tibialis anterior transplant to the lateral border of the foot, and two feet $(2 \%)$ also had a Steindler soft-tissue release.

In 28 clubfeet considered to be corrected by conservative management I was unable to accept that lasting correction had been obtained. This group included 12 feet $(11 \%)$ treated by
Denis Browne splints ; 14 feet (14\%) treated by Robert Jones's stretching and strapping; and 2 feet $(10 \%)$ treated with serial plasters. In four of these cases treated by Robert Jones's stretching and strapping it appeared that operation had been postponed for too long, and it could no longer produce a normal foot.

In 85 feet $(81 \%)$ treated by Denis Browne splints conservative treatment was unsuccessful, whereas 68 feet $(71 \%)$ were treated successfully by Robert Jones's stretching and strapping alone. None of the feet treated with serial plasters was considered to be corrected, but the number is too small to enable one to be didactic.

A detailed analysis of the groups is shown in Table II.

TABLE II.-Results of Primary Treatment

\begin{tabular}{|c|c|c|c|}
\hline & $\begin{array}{c}\text { Denis Browne } \\
\text { Splint }\end{array}$ & $\begin{array}{l}\text { Robert Jones's } \\
\text { Strapping }\end{array}$ & $\begin{array}{c}\text { Serial } \\
\text { Plasters }\end{array}$ \\
\hline $\begin{array}{l}\text { No. of feet treated successfully } \\
\text { by conservative treatment } \\
\text { No. of feet treated by operation } \\
\text { after unsuccessful conservative } \\
\text { treatment } . . \\
\text { No. of feet not corrected by } \\
\text { conservative treatment but } \\
\text { operation withheld ... }\end{array}$ & $\begin{array}{l}20(19 \%) \\
73(70 \%) \\
12(11 \%)\end{array}$ & $\begin{array}{l}14(14 \%) \\
14(14 \%)\end{array}$ & $\begin{array}{l}18(90 \%) \\
2(10 \%)\end{array}$ \\
\hline Total $\quad \ldots$ & 105 & 96 & 20 \\
\hline
\end{tabular}

\section{Discussion}

Congenital talipes equinovarus is a congenital dislocation of the talo-calcaneo-navicular joint. Failure to reduce the dislocation prevents the normal development of the tarsal bones from their cartilaginous anlages. As the tarsal bones can change shape rapidly, reduction must be accomplished within the first two or three months of life. Early, accurate, and sustained reduction is therefore essential for satisfactory results.

This analysis of the three primary methods of treatment shows the outstanding merit of repeated gentle stretching and fixation with adhesive strapping. It has been stated that with this method no fixed point is available to anchor the foot, and that it is impossible to correct properly the bending in the forefoot in relation to the body as a whole by means of stickingplaster. This is a misconception of the principle of the method. The strapping is simply a means of holding the foot in the correct position after it has been stretched, and the fixed point is obtained by carrying the strapping around the flexed knee. The further suggestion that the application of strapping around a flexed knee produces knock-knee by stretching of the internal lateral ligament is fallacious. No case of knock-knee was seen in the present series of cases treated with stretching and adhesive strapping as described by Jones and Lovett (1929).

In the present series of patients the chief obstacle to primary correction was the persistent equinus deformity of the calcaneum. This was more obvious in the feet treated with Denis Browne splints than in those treated by stretching and adhesive strapping. The principal reason for this is the failure of the Denis Browne splint to control the equinus deformity of the calcaneum, a difficulty which is enhanced by the smallness of the heel.

Bell and Grice (1944) in particular emphasize the problems encountered in treating 53 patients with uncomplicated talipes equinus with their modified Denis Browne splint: these included pressure sores, dermatitis, incomplete correction, persistent equinus, and loss of the longitudinal arch, and unilateral deformity. In the present series persistent equinus of the calcaneum and the development of a rocker-bottom foot due to a breach at the calcaneo-cuboid joint were all too rommon. Similarly, rocker-bottom foot was occasionally encountered after treatment by stretching and strapping, but far less often than after using the metal splint. The failure to correct the calcaneal equinus is the cause of the failure to reduce the head of the talus into the navicular bone (Elmslie, 1920). 
It is surprising that, except in Brockman's (1930) monograph, none of the communications on the results of primary management of clubfoot present a statistical analysis. Those surgeons who use the Denis Browne splint or a modification claim to have very gratifying results (Browne, 1937, 1956 ; Bell and Grice, 1944 ; Thomson, 1949). However, in a recent survey by McCauley, Lusskin, and Bromley (1964), these workers stated that: "Because of the development of flat-foot following treatment in some of the patients we question the use of the Denis Browne splint as a corrective device."

In the light of the present findings it is suggested that the numerous modifications which have been devised for the Denis Browne splint (Thomson, 1942, 1949 ; Bell and Grice, 1944) disclose the discontent with the results obtained by its use. There is a paucity of statistical evidence in the literature on the efficiency of the splint. Its virtues are much vaunted, its weaknesses concealed.

The statistics of the present survey on the treatment by stretching and Robert Jones's strapping compare favourably with those of Brockman (1930), who used a similar method: in 73 patients $50.6 \%$ required only manipulation and strapping to cure the deformity ; $20.5 \%$ also had division of the tendo calcaneus with plaster splintage ; $24.6 \%$ were not cured by either of these methods and required some form of open operation; $4.1 \%$ still retained this deformity after all these methods and an operation on bone was performed. His later despondency (Brockman, 1937) was hardly warranted by the quality of his results.

More recently Thomas (1964) claims that $90 \%$ of patients can be cured by simple manipulation followed by splinting, if the baby is treated daily as soon after birth as possible.

The evidence presented here leaves no doubt that the successful treatment of talipes equinovarus must begin at birth.

Though it is not invariably successful, repeated gentle stretching and the application of adhesive strapping to maintain correction is a more satisfactory technique than either the Denis Browne splint or serial plaster-of-Paris casts. We have been too easily persuaded to relinquish Robert Jones's method of treatment, which, apart from its high rate of success, has the merit of simplicity and the additional appeal of being old-fashioned.

\section{Summary}

Three different methods for the primary treatment of congenital clubfoot have been compared. These methods were the Denis Browne splint, stretching and adhesive strapping, and serial plaster-of-Paris casts. There were 140 patients in the series and 221 feet were affected. Only 20 (19\%) of 105 feet were successfully treated by the Denis Browne method alone, whereas 68 feet out of $96(71 \%)$ were treated successfully by stretching and strapping. None of the 20 feet treated by manipulation and serial plaster-of-Paris casts could be regarded as corrected. These results show that splintage alone is of little value for the correction of clubfoot deformity and that correction followed by fixation with adhesive strapping is far more effective.

I owe my gratitude to Mr. G. C. Lloyd-Roberts and Mr. H. H. Nixon for their encouragement and help during this survey of their patients. My thanks are also due to Mr. R. A. Denham, of the Royal Hospital, Portsmouth, for his generosity in allowing me to review the patients under his care.

\section{REFERENCES}

Bell, J. F., and Grice, D. S. (1944). F. Bone ft. Surg., 26, 799. Brockman, E. P. (1930). Congenital Club-Foot. Wright, Bristol. - (1937). Brit. med. 9., 2, 572 .

Browne, D. (1937). Ibid., 2, 570.

- (1956). Clinical Orthopaedics-No. 8. Lippincott, Philadelphia. Elmslie, R. C. (1920). F. orthop. Surg., 28, 668.

Jones, R (1894). Trans. Brit orthop Soc, 120.

and Lovett, R. W. (1929). Orthopaedic Surgery, 2nd ed. Oxford University Press, London.

McCauley, J., Lusskin, R., and Bromley, J. (1964). F. Bone ft. Surg. 46A, 525 .

Thomas, G. E. (1964). Ibid., 46B, 792.

Thomson, S. A. (1942). Ibid., 24, 291.

(1949). Ibid., 31A, 431.

\title{
Hepatic Dysfunction in the Congenital Rubella Syndrome
}

\author{
GILLES R. G. MONIF,* M.D. ; RICHARD ASOFSKY,* M.D. ; JOHN L. SEVER,* M.D., PH.D.
}

Brit. med. F., 1966, 1, 1086-1088

The congenital rubella syndrome once defined a morphologically static condition: specific malformations which were the sequelae of maternal infection with rubella virus early in gestation. It is now apparent that this term is conceptually limited, and must be expanded to include an "acute" component due to continued virus action in the neonatal period and beyond (Alford et al., 1964 ; Monif et al., 1965). Thrombocytopenia, encephalitis, interstitial pneumonia, myocardial injury, and hepatitis have all recently been described in infants with the rubella syndrome (Rudolph et al., 1965 ; Korones et al., 1965 ; Hardy et al., 1966). It is the purpose of this paper to characterize the hepatitis more completely.

\section{Materials and Methods}

Six cases of congenital rubella syndrome, confirmed by virus isolation from either throat or urine specimens, were identified in which, in addition to the classical stigmata of the rubella syndrome, there was evidence of hepatic dysfunction. Two of the six infants with biochemical evidence of hepatic dysfunction came to necropsy. In addition to the review of the clinical data and histological analysis, the livers from these two infants and a percutaneous liver biopsy specimen from a third infant were studied for the recovery of virus.

The two livers were homogenized in Hanks's balanced salt solution containing penicillin, 400 units $/ \mathrm{ml}$., and streptomycin, $0.4 \mathrm{mg} . / \mathrm{ml}$; ; and then the homogenate was diluted to a $20 \%$ suspension. Each specimen was then centrifuged at $600 \mathrm{~g}$. for 15 minutes, and $0.2-\mathrm{ml}$. aliquots of the supernatant were inoculated into four primary African green monkey kidney cultures in roller tubes. The cultures were maintained with $1.5 \mathrm{ml}$. of medium consisting of Eagle's basal medium con-

* From the Section on Infectious Diseases, Perinatal Research Branch, National Institute of Neurological Diseases and Blindness, and the National Institute of Neurological Diseases and Blindness, and the Laboratory of Infectious Diseases, National Institutes of Allergy and Maryland. 